\title{
Visuospatial functions in the rat following injuries to striate, peristriate, and parietal neocortical sites
}

\author{
WILLIAM F. MCDANIEL and TINA TERRELL WALL \\ Georgia College, Milledgeville, Georgia
}

\begin{abstract}
The influence of lesions located generally within four regions of the rat's posterior neocortex upon the acquisition and retention of two-choice visual discriminations was assessed using a Thompson-Bryant apparatus. The ability to distinguish visual patterns was tested by utilizing stimuli composed of $45^{\circ}$ versus $135^{\circ}$ alternating black and white stripes (both total and local luminance cues were controlled). "Brightness" discrimination was assessed by using black and white card discriminanda. Posterior parietal injuries resulted in a dysfunction on each of the four tasks, but rats with this injury eventually attained criterion for each of the habits. Smaller, more anteromedial parietal lesions failed to disturb pattern discrimination and were not studied in the other paradigms. The only deficit observed in rats with medial peristriate injuries was a slight retardation in acquisition of the pattern discrimination. Since the effects of lateral peristriate and striate injuries upon pattern vision have been well described previously, the effects of these lesions on the retention and acquisition of the black-white discrimination were studied. Lateral peristriate lesions, but not striate lesions, were associated with a retention loss of the brightness problem. This loss was detected even with a recovery interval of 60 days. Both striate and lateral peristriate lesions retarded black-white discrimination acquisition. Discussion focuses on the probable natures of the visual dysfunctions associated with these injuries.
\end{abstract}

Ablation of the rat's posterior neocortex has been reported to produce an abolition of form vision (e.g., Horel, Bettinger, Royce, \& D. R. Meyer, 1966; Lavond \& Dewberry, 1980; Lavond et al., 1978) and a retention loss of a preoperatively acquired black versus white card discrimination (e.g., LeVere, 1980; D. R. Meyer \& P. M. Meyer, 1977). On the basis of the former evidence, it has been argued that visual pattern perception is a cortically dependent function in the rat, and that previous demonstrations of residual form-perception abilities following posterior decortication were due to the common use of stimuli that contain confounding nonpattern cues such as differences in local flux. However, many visual functions survive posterior decortication. For example, Whishaw and Kolb (1984) reported that rats with total decortication, which in some cases included the hippocampectomy, were able to learn to swim to a visible platform in the Morris water task. These animals were incapable of utilizing extramaze visual cues to locate a submerged (and hence invisible) escape platform. Also, Goldstein and Oakley (1987) have recently reported that two of six to-

Three faculty research grants to the first author, funded by the Georgia College Foundation, made this work possible. We wish to thank the following persons for assistance in the collection of behavioral data: Melanie Giddens, Melba Brown, Bill Sandefur, and Valerie Patterson. An earlier version of the present paper was presented at the IBRO Symposium “Extrageniculostriate Visual Mechanisms,"' Szeged, Hungary, August 22-24, 1987. Communication should be addressed to William F. McDaniel, Department of Psychology, Georgia College, Milledgeville, GA 31061. tal decorticates and four of six posterior decorticates were able to learn a pattern discrimination that equated both total and local luminance flux. Demonstration of this residual visual discrimination ability required extensive postoperative training (i.e., 12 to 14 times the number of training trials required by sham-operated controls) and the use of food rather than shock motivation. Despite the latter observation, it is apparent that injuries located in the posterior neocortex seriously disrupt the rat's ability to utilize visual cues.

The posterior decortication preparation inflicts damage on a number of sites that might be distinguished on the bases of both anatomical and electrophysiological criteria (see McDaniel, 1985, for a review). The principle focus of the investigations reported here was the possibility that subtotal injuries confined generally to five divisions of the posterior neocortex might produce different effects upon the abilities of rats to utilize visual cues to guide instrumental behavior. The subtotal injuries examined were located in the striate (area 17), medial peristriate (MP; area 18b), lateral peristriate (LP; area 18a), posterior parietal (PP; areas 7, 39, and caudal portions of area 3), and anteromedial parietal (AMP; area 3) neocortices.

Some progress has already been achieved toward the goal of contrasting the behavioral deficiencies associated with striate as opposed to LP lesions. Both removal (Dean, 1981; Gallardo et al., 1979; McDaniel, Coleman, \& Lindsay, 1982; McDaniel \& Noble, 1984) and deafferentation (Hughes, 1977) of the LP cortex, which contains at 
least four retinotopically organized regions (Espinoza \& Thomas, 1983), produce a dysfunction in visual pattern perception more severe than that produced by striate injuries. Not only do LP lesions encompass less of the neocortical surface than striate lesions, but they produce minimal retrograde degeneration in the lateral geniculate nucleus. Recently it has been suggested (Lindsay \& McDaniel, 1987) that the LP neocortex might play a necessary role in visual pattern perception. In this study, rats with LP lesions failed to acquire a discrimination of $35^{\circ}$ versus $145^{\circ}$ alternating black and white stripes, although they received a range of 1,000 to 1,500 training trials. Lesions limited to the LP, but not striate, neocortex produce the classic (Lashley, 1935) retention loss of a preoperatively acquired black- versus white-card (i.e., brightness) discrimination (McDaniel et al., 1982). Behavioral disturbances associated with LP damage may be confined to tasks involving the utilization of visual cues, since animals with this injury acquire a series of blackwhite reversals slowly, although they parallel normal rats in their rate of acquisition of spatial reversals (McDaniel \& Thomas, 1978). Finally, striate but not LP injuries produce a deficit in the postoperative performance of a preoperatively acquired radial maze habit (McDaniel \& Brown, 1984). Hence, the striate cortex may be responsible for the spatial functions previously ascribed to the "occipital" neocortex (Foreman \& Stevens, 1982; Goodale \& Dale, 1981; Thompson, 1979).

Investigations of the effects of selective MP lesions have been few. Pinto-Hamuy et al. (1987) recently reported that rats with injuries located in the anteromedial portions of area $18 \mathrm{~b}$ (i.e., MP) failed to retain and relearn a preoperatively acquired conditional visuosomatic discrimination. In this study, the texture of surfaces in the training chamber (smooth or rough) cued whether a white or black card would be associated with food. Rats with striate, LP, or auditory cortex damage were able to either retain or relearn the habit. Apparently there have been no attempts to study the effects of injuries within this retinotopically organized region (Espinoza \& Thomas, 1983; Montero, Rojas, \& Torrealba, 1973) upon pattern and black-white discriminations.

Injuries located principally in area 3 of the PP cortex have been associated with impaired retention of the Lashley III maze (Thomas \& Weir, 1975), impaired acquisition of the Hebb-Williams mazes (Boyd \& Thomas, 1977), and retarded acquisition of a series of spatial reversals (Kolb, Sutherland, \& Whishaw, 1983; McDaniel \& Thomas, 1978). Rats with this injury are relatively unimpaired in the acquisition and postoperative retention of the Morris water task, the 8-arm radial maze (Kolb et al., 1983; McDaniel \& Brown, 1984), and visual discriminations (McDaniel, 1985; McDaniel, Wildman, \& Spears, 1979). However, more recently Kolb and Walkey (1987) reported that PP injuries located mainly in area 7 resulted in a constellation of behavioral deficits relative to nor- mal controls. These included retarded acquisition of the 8-arm radial maze, a tactile discrimination problem, tasks requiring accurate navigation to an uncued point in the Morris water task, and a task in the water maze that required the animals to associate spatially discontiguous stimuli. The abilities of the animals to navigate to a visually cued platform in the water task and to open puzzle latches were not disturbed. These results led the authors to conclude that area 7 of the PP cortex might be considered an analogue of the PP cortex in primates. Therefore, another goal was to compare the effects upon pattern discrimination of a more anteromedial parietal lesion, which damaged primarily area 3 , with the effects of the more posterior injury, which damaged principally areas 7 and 39. One might expect a disturbance in pattern vision to result from the latter lesion, since many corticocortical fibers from the visual cortex terminate here (Miller \& Vogt, 1984) and since photic stimulation increases the utilization of glucose by neurons in this region (Toga \& Collins, 1981). As a qualifying prelude, it should be appreciated that the small size and lissencephalic morphology of the rodent neocortex prevented the placement of mutually exclusive injuries in many preparations.

\section{METHOD}

\section{Subjects}

One hundred and forty male and female hooded rats of the LongEvans strain, bred here and ranging in age from 90-150 days at the beginning of the experiments, were used. The animals had been individually housed since $\mathbf{4 5}$ days of age, and they were entrained to a reversed light-dark cycle with light offset at 7:00 a.m. and onset at 8:00 p.m. Ad-lib access to food and water was permitted.

\section{Surgery}

Following an intraperitoneal injection of Nembutal (sodium pentobarbital; $50 \mathrm{mg} / \mathrm{kg}$ for females, $55 \mathrm{mg} / \mathrm{kg}$ for males), the scalp was shaved and scrubbed with a $10 \%$ USP Povidone-iodine solution. The rat was mounted in a Kopf stereotaxic instrument, and a midline scalp incision was made. The underlying fascia was retracted with a periosteal elevator; and for animals receiving PP and LP lesions, the temporalis muscle was dissected bluntly from the temporal ridge. At this point, the animals designated for sham lesions had their wounds closed with either wound clips or sutures; Mycitracin triple antibiotic was liberally applied to the incision.

The following cranial landmarks were used to achieve access to the neocortical regions of interest. The LP lesions were made by first drilling the skull $3 \mathrm{~mm}$ rostral to the lambda suture, and centered on the temporal crest, with a $2.5-\mathrm{mm}$ trephine. The opening was enlarged with rongeurs in the rostral-to-caudal direction, to approximate the shape of the LP neocortex (Torrealba, Olavarria, \& Carrasco, 1984). Posterior parietal lesions were similar to those described by Kolb and Walkey (1987). A trephine hole was drilled approximately $3.0 \mathrm{~mm}$ posterior to bregma and $1.5 \mathrm{~mm}$ lateral to the sagittal suture. Rongeurs were then used to extend the cranial opening 6.0 to $7.0 \mathrm{~mm}$ lateral to the sagittal suture, perpendicular to the temporal ridge. The AMP lesions were made by drilling the skull $1 \mathrm{~mm}$ posterior to bregma and $1.5 \mathrm{~mm}$ lateral to the sagittal sulcus and aspirating the underlying cortex. For striate injuries, the trephine hole was drilled $3.0 \mathrm{~mm}$ lateral to the sagittal suture and $3.0 \mathrm{~mm}$ anterior to lambda. Again, rongeurs were used to ex- 
pand the opening to approximate the shape of area 17 (Hughes, 1977). Access to the MP cortex was achieved by centering the trephine 1.5 to $2.0 \mathrm{~mm}$ lateral to the sagittal suture and $3.0 \mathrm{~mm}$ anterior to lambda. Microrongeurs were used to expand the opening to approximate the shape of area $18 \mathrm{~b}$, as described by Torrealba et al. (1984).

The dura was incised with a microdissection knife, and in an attempt to minimize callosal damage, the cortical mantle underlying the opening was aspirated through a $1.5-\mathrm{mm}$ pipette under visual guidance of a surgical microscope. When excessive bleeding occasionally occurred, the cavity was packed with Gelfoam. The wound was then closed, as it was for sham-operated rats. All instruments used in surgery were sterile.

\section{Histology}

Following behavioral testing, the animals with lesions were given an overdose of Nembutal $(.70 \mathrm{cc})$ and perfused through the heart, first with $50 \mathrm{ml}$ of $0.85 \%$ saline and then with $50 \mathrm{ml}$ of $10 \%$ formalin. The whole brain was then removed and placed in formalin for several days before being photographed from the dorsal view through a 55-mm Macro lens. The brains were blocked to include the lesion site and thalamus and soaked under refrigeration for a minimum of 3 days in a $30 \%$ sucrose- $10 \%$ formalin solution. The blocked brains were frozen in a Cryocut II microtome and sectioned through the coronal plane at a thickness of $40 \mu \mathrm{m}$. Every 5 th (in Experiments 1 and 4) or 10th (in Experiments 2, 3, and 5) section was mounted on a slide, which was later stained with cresyl-violet acetate. These coronal sections were then examined under a light microscope to determine the lesion depth and the pattern of thalamic necrosis.

\section{Conditioning Apparatus and Stimuli}

A modification of the two-choice discrimination chamber described by Thompson and Bryant (1955) was used. The startbox and choice arena together formed a $Y$ shape such that the junction between compartments was $15 \mathrm{~cm}$ wide and angled outward toward a rear wall $65 \mathrm{~cm}$ wide. Perpendicular to the rear wall of the choice arena was a divider wall that extended $22 \mathrm{~cm}$ toward the startbox, dividing the choice arena into two symmetrical compartments. Exit to the goalbox $(21 \times 45 \mathrm{~cm})$ was possible through either a right or a left side-hinged Plexiglas door $(9 \times 12 \mathrm{~cm})$, which also served as a stimulus holder for the visual stimuli. The remainder of the rear wall of the choice arena was wood. The distance from the startbox to the goalbox doors was $66 \mathrm{~cm}$. All the compartments were divided by guillotine doors. The entire apparatus was painted gray, except for the floor of the startbox and choice arenas, which consisted of 0.64-cm-diam zinc-coated steel bars. Each bar was wired to a neon grid-scrambler output, which was in turn wired to a constant-current shocker. A double-pole toggle switch allowed separate delivery of mild footshock to the startbox and choice arena. Ilumination was provided by two 15 -W fluorescent tube lamps, located above and behind the goalbox doors.

The pattern stimuli consisted of alternating black and white stripes $1.25 \mathrm{~cm}$ wide, oriented $45^{\circ}$ and $135^{\circ}$ to horizontal. These stimuli were designed to equate total luminance cues, and local flux cues were controlled by creating pairs of stimuli in which one member of each pair had a black stripe in the location of a white stripe on the complementary card. The black-and-white-card stimuli for training in brightness discrimination were made from construction paper. All the stimuli were mounted in rigid, translucent holders.

\section{Training}

Prior to being shaped to discriminate visually, all animals were gentled by five daily 15 -min handling sessions. Next, the animals were allowed to explore the apparanus with all doors open for a 15-min session. On the following day, a shaping procedure began, in which, across the next 2 or 3 days, the rats were trained to run from the start compartment to the goalbox in order to avoid footshock $(.25-.35 \mathrm{~mA})$. The goalbox doors were initially left open, but then were gradually closed across successive trials. Neutral gray cards occupied the stimulus holders during all pretraining trials

After attaining a pretraining criterion of eight consecutive nonshocked runs from the start- to goalbox, the rats were trained to discriminate visual stimuli located in the goalbox doors. For brightness discrimination training, the white card was positive for one half of the animals and the black card was positive for the other half. For pattern discrimination experiments, the $45^{\circ}$ striped cards were correct for one half of the animals and the $135^{\circ}$ striped cards were correct for the other half. Approaches to within $4 \mathrm{~cm}$ of the negative door were punished with footshock that remained on until the animal corrected its response. When an error was committed, the positions of the stimuli remained unchanged on successive runs until a correct choice was observed. Only then did the trainer begin the next trial. The major dependent variable was total errors to criterion-that is, initial errors plus any perseveration errors committed on correction runs. The right or left positions of the stimuli were determined by a Fellows (1967) series; the animals were administered 20 trials (not including correction runs) per session. The rats were trained 5 days per week. The criterion to demonstrate acquisition and retention of all discriminations was established as two consecutive nuns of nine correct first trial choices within a sequence of 10 trials. Daily feeding followed training sessions. All training was conducted at approximately the same time each day and during the dark phase of the reversed dark-light cycle.

For experiments concerning the retention of a preoperative habit, surgery was performed within a range of 3 to $28 \mathrm{~h}$ after acquisition. In these studies, the lesion groups were matched on the basis of the total preoperative acquisition errors and the sex of the rat. In all the experiments, the trainers were "experimenter blind" concerning the locus of the animals' injuries.

\section{Procedure}

Five experiments were performed. The first two involved pattern discrimination and the latter three concerned the brightness discrimination.

Experiment 1. Twenty-four male rats were trained to discriminate the visual patterns. They were then divided into four groups, matched on the basis of preoperative errors, and prepared with PP, AMP, MP, or sham injuries. Retention testing began 12 to 14 days following surgery. One day after attaining criterion in the retention test for pattern vision, the animals were trained on the series of four problems shown in Figure 1. One half of the animals in each group were trained according to sequence $A$ and one half were assessed with sequence $B$. The masking stimuli consisted of a 4.5cm-high irrelevant back bar or horizontal stripes. Locating mask-

\section{Training Sequence}

ค

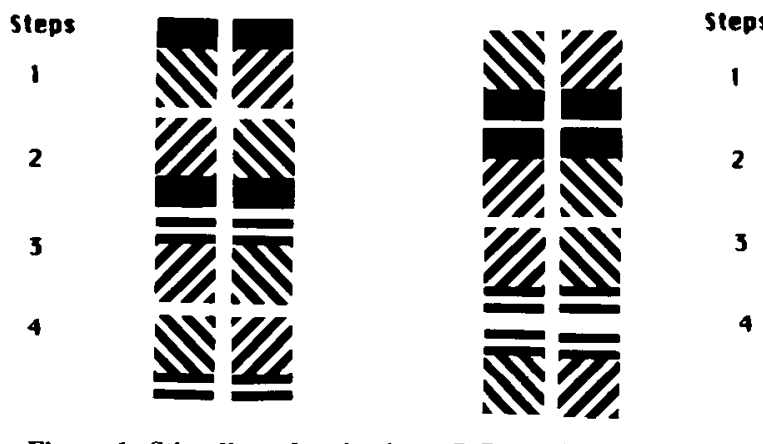

Figure 1. Stimuli used to institute $\mathbf{S}-\mathbf{R}$ spatial discontiguity. 
ing stimuli in the rat's visual field, that is, in the lower portion of the stimulus card (where rats usually direct their door opening response), has been described as an $\mathrm{S}-\mathrm{R}$ spatial discontiguity task sensitive to some spatial dysfunctions. (P. M. Meyer, D. R. Meyer, \& Cloud, 1986; Milner, Goodale, \& Morton, 1979). Criterion for each problem was nine correct responses within 10 consecutive trials.

Experiment 2. Rats with PP $(n=10)$, MP $(n=10)$, or sham $(n=7)$ injuries were trained to criterion to discriminate the oblique stripes. There were 3 males in the lesion groups and 2 males in the sham group.

Experiment 3. Rats were trained on the brightness problem and, on the basis of preoperative errors, assigned to one of five matched groups. Each lesion group (striate, LP, MP, PP) contained an $n$ of 6,3 of which were female. The sham-operated group had an $n$ of 4,2 of which were female. Following a 10 - to 11 -day postoperative recovery interval, retention of the preoperative habit was assessed.

Experiment 4. In light of Gavin and Isaac's (1986) report that posterior decorticates show complete recovery of a preoperatively acquired light-onset-cued avoidance habit if allowed a minimum of 20 days to recover postoperatively, it was deemed important to investigate the duration of the brightness retention deficit induced by the LP lesion. Hence, 36 rats were trained on the black-white discrimination and then assigned to one of six factorial groups that were matched on the basis of preoperative errors and gender. The independent variables were brain injury (LP or sham) and recovery interval $(20,30$, or 60 days).

Experiment 5. Rats were assigned quasi-randomly to five surgical conditions and prepared with striate, PP, MP, LP, or sham injuries. Three of the 5 animals in each group were female.

\section{RESULTS}

\section{Histology}

Photographs depicting the lesions in representative cases from the dorsal perspective are shown in Figure 2. Generally the lesions were well-placed. The proportion of the cortical mantle visible from the dorsal perspective that was removed in creating the lesions was estimated by the dot-grid method (Thomas \& Peacock, 1965). The variation according to this measure was relatively low within each of the lesion groups, and most of the animals varied from the average by $1 \%$ or $2 \%$. Pooled across all experiments, the lesions ranged in size, from lowest to highest as follows: PP, 0.20 to 0.28 ; AMP, 0.15 to 0.19 ; MP, 0.08 to 0.15 ; striate, 0.19 to 0.26 ; and LP, 0.07 to 0.15 .

Microscopic evaluations of the sectioned brains revealed that only one of the injuries produced direct damage to structures below the level of the corpus callosum. In fact, callosal damage was rare in all the lesion groups, except for the rats prepared with PP and striate lesions. A single animal with a PP lesion sustained damage to the dorsal portions of the right hippocampus. Figure 3 shows photographs of three cresyl-violet-stained coronal sections in representative brains.

The only thalamic retrograde degeneration that accompanied MP lesions was occasional mild gliosis in the lateral geniculate nucleus. The AMP lesions resulted in dense gliosis in the posterior thalamic nucleus and scat- tered gliosis in the ventral complex. Less dense gliosis was observed in the lateral thalamic nucleus. The pattern of degeneration described for AMP lesions was also observed following PP lesions, but denser gliosis was observed in both the ventral complex and the lateral thalamic nuclei. Mild gliosis in the lateroposterior nucleus accompanied LP injuries. It was not uncommon to observe dense gliosis and cell loss in the dorsomedial border of the lateral geniculate and lateroposterior nuclei. Striate injuries resulted in prominent neuron loss and gliosis in the lateral geniculate nucleus. Surviving neurons remained in some animals; but these cells generally appeared shrunken, and they stained weakly.

\section{Behavior}

The dependent variable selected for analysis in all experiments comprised the total errors through the criterion run. This figure represents the sum of the errors made on each trial of the Fellows (1967) series (initial errors), plus any errors made on correction runs (perseveration errors). It is suggested that this is an appropriate measure, since one-way analyses of variance (ANOVA) on the ratio of perseverative errors to total errors conducted on the postoperative acquisition data from Experiments 2 and 5 failed to differentiate the groups $[F(2.24)=1.48$, $p>.10$, and $F(4,20)=1.02, p>.10$ ], respectively. Similar analyses of the retention data would not have been productive, because of the excellent savings seen in many animals. Finally, analyses of initial errors produced similar statistical results.

Experiment 1. A one-way ANOVA on the preoperative total acquisition errors confirmed that the matching procedure had resulted in equivalent groups $[F(3,20)=$ $0.13, p>.10]$. The overall mean number of errors was 42. A one-way ANOVA on postoperative total errors was significant $[F(3,20)=17.85, p<.01]$. Fishers $L S D$ test showed that the PP grop made more postoperative errors $(M=28)$ in reattaining criterion than did any of the other lesion groups $[M$ overall $=3.39 ; t(20)=7.28, p<.01]$. No differences in retention were seen between the MP, AMP, and sham-operated groups; all showed substantial savings (see Figure 4a).

Separate split-plot factorial ANOVAs (lesions $\times$ masking stimulus location) were computed on total errors to criterion for problems with bar and horizontal-stripe masking stimuli. Both analyses failed to reveal differences between lesion groups. However, in both analyses the repeated measures factor was significant $[\mathrm{bar}, F(1,20)=$ $4.39, p<.05$; horizontal stripes, $F(1,20)=5.25$, $p<.05]$, indicating that more errors were made by all groups when the masking cue occupied the lower $4.5 \mathrm{~cm}$ of the stimulus card (bar, $M$ overall $=5.42$; horizontal stripes, $M$ overall $=4.0$ ) than when it occupied the upper $4.5 \mathrm{~cm}$ (bar, $M$ overall $=2.75$; horizontal stripes, $M$ overall $=1.29$ ). These latter findings confirm the sensitivity of this methodology in creating an S-R spatially 

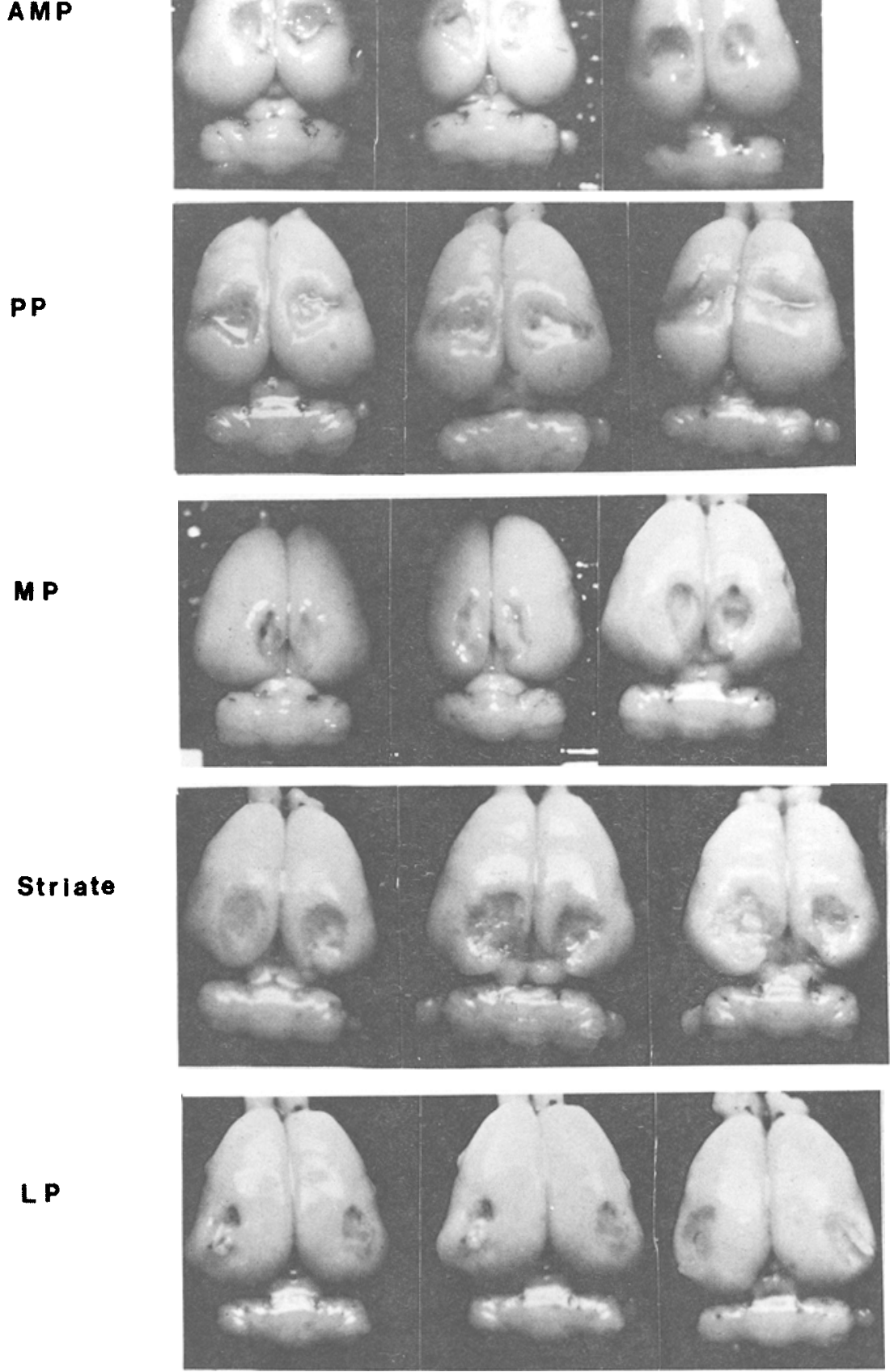

Figure 2. Photographs depicting representative cases of each of the lesions studied in these experiments. Abbreviations: $\mathbf{A M P}=$ anteromedial parietal, $\mathbf{P P}=$ posterior parietal, $\mathbf{M P}=$ medial peristriate, $\mathbf{L P}=$ lateral peristriate.

discontiguous task, but failed to support the hypothesis that rats with posterior parietal lesions might demonstrate a prominent disability in solving problems that involve difficult spatial relations.

Experiment 2. A one-way ANOVA on total errors to criterion revealed a significant between-lesion-group effect $[F(2,24)=3.48, p<.05]$. Fisher's $L S D$ test showed that both the MP ( $M=48.5)$ and the PP $(M=51.2)$ groups committed more errors than the sham-operated group $(M=36.6)[t(24)=2.07, p<.05$, and $t(24)=$ $2.54, p<.05$, respectively] (see Figure $4 \mathrm{~b}$ ).

Experiment 3. An ANOVA on total errors ( $M$ overall $=28$ ) to criterion prior to surgery was nonsignificant $[F(4,23)=1.37, p>.05]$. An ANOVA on postopera- 


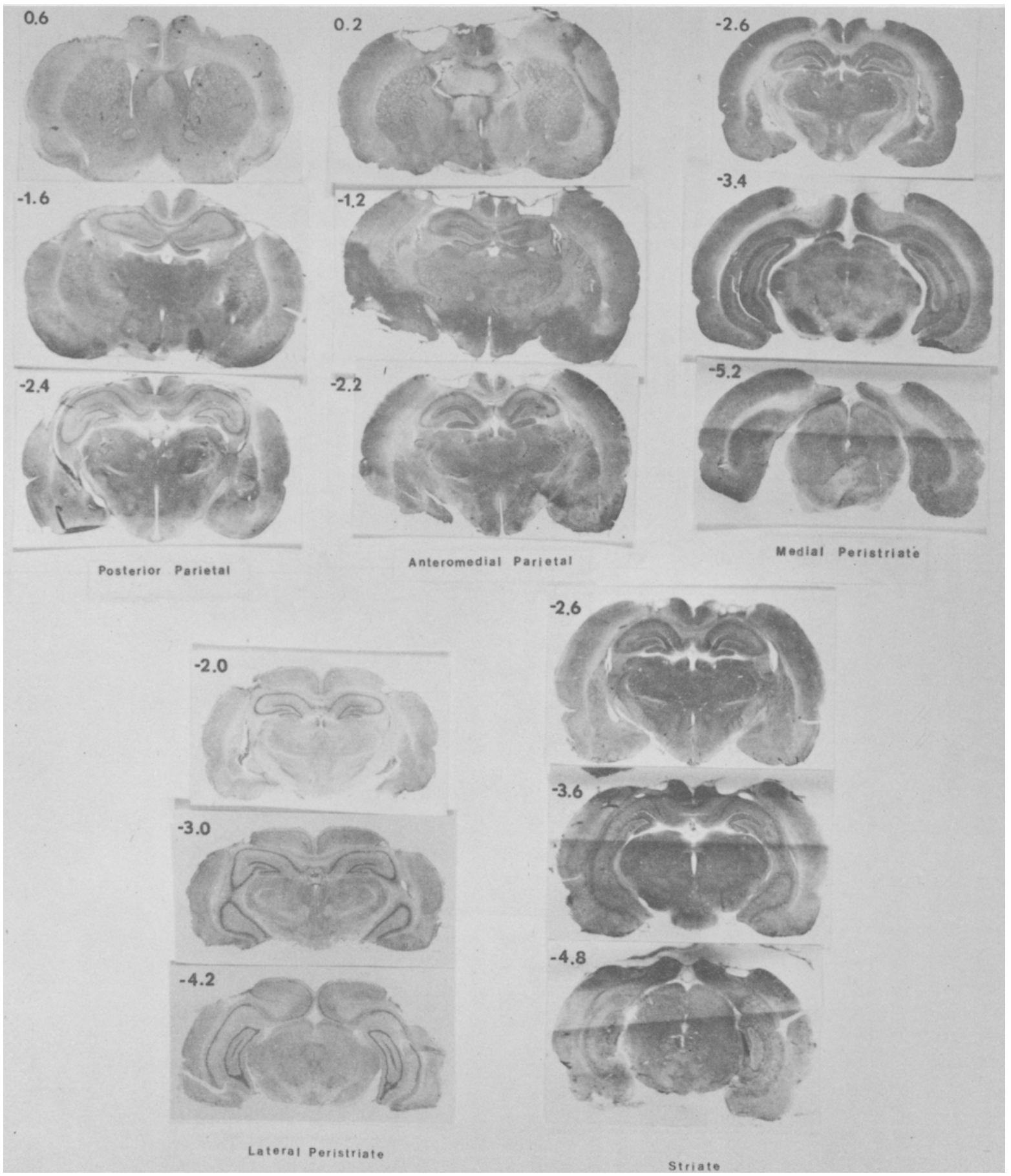

Figure 3. Cresyl-violet-stained coronal sections through brains representative of each of the lesions. Numerals in the upper left of each photograph concern millimeters anterior (positive values) or posterior (negative values) to bregma.

tive retention errors was, however, significant $[F(4,23)$ $=3.69, p<.05]$. Fisher's $L S D$ tests showed that the LP $(M=13.67)$ and PP animals $(M=12.00)$ committed more errors (all $p s<.05)$ than the striate $(M=4.33)$, MP $(M=3.67)$, and sham-operated groups $(M=2.00)$ (see Figure 5a). Interestingly, neither the striate nor the MP groups differed from the sham control animals.
Experiment 4. A two-way ANOVA on preoperative acquisition errors was nonsignificant for both factors and the interaction, showing that the groups had been successfully matched prior to surgery. A two-way ANOVA on total postoperative errors to criterion revealed only a significant main effect for lesion location $[F(1,30)=16.59$, $p<.01]$. That is, the rats with LP lesions $(M=25)$ com- 
A

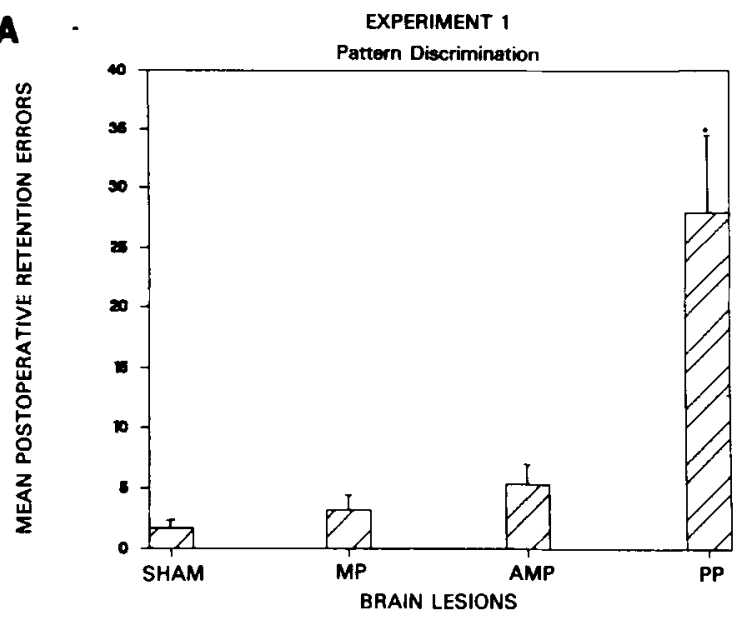

B

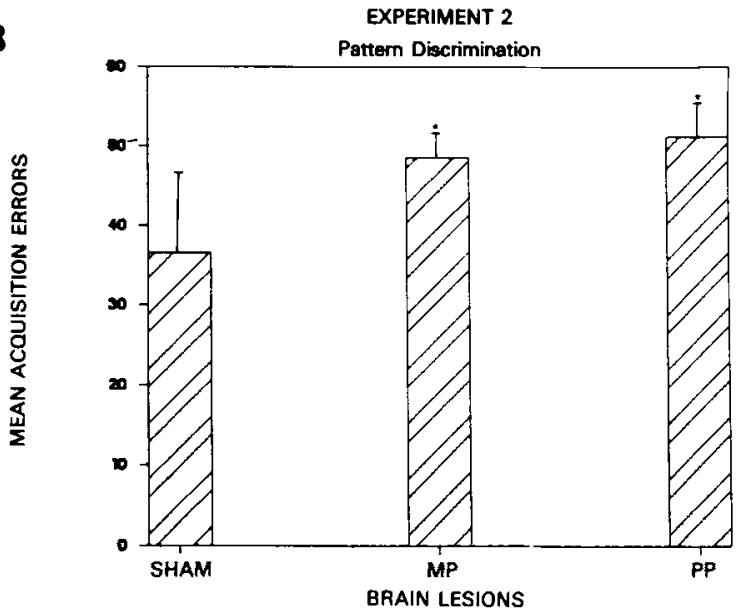

Figure 4. Mean and standard error of the mean total errors on the oblique stripe pattern discriminations. Asterisks indicate significant differences from sham controls. Panel A, retention; Panel B, acquisition.

mitted more errors than did sham-operated rats $(M=6)$. The nonsignificant interaction of lesion $\times$ recovery interval length $[F(2,30)=0.85]$ demonstrates that the lesion-induced retention loss was detectable even with a recovery interval of 60 days (see Figure $5 b$ ). Hence, Gavin and Isaac's (1967) recovery findings do not generalize to the two-choice brightness discrimination problem.

Experiment 5. An ANOVA on total errors to criterion was significant $[F(4,20)=2.94, p<.05]$. Fishers's $L S D$ test revealed that rats with LP injuries made more errors $(M=57.6)$ than rats with sham $(M=28.6)$ and MP ( $M$ $=29.2)$ lesions $[t \mathrm{~s}(20)=2.89$ and 2.84 , respectively; $p s<.05]$. No other differences achieved statistical significance. Because of the near equivalence of the sham and MP means, it might be argued that it would be reasonable to pool these groups to form a single control group. The same argument might be applied to the PP and striate groups since their means were markedly similar
A

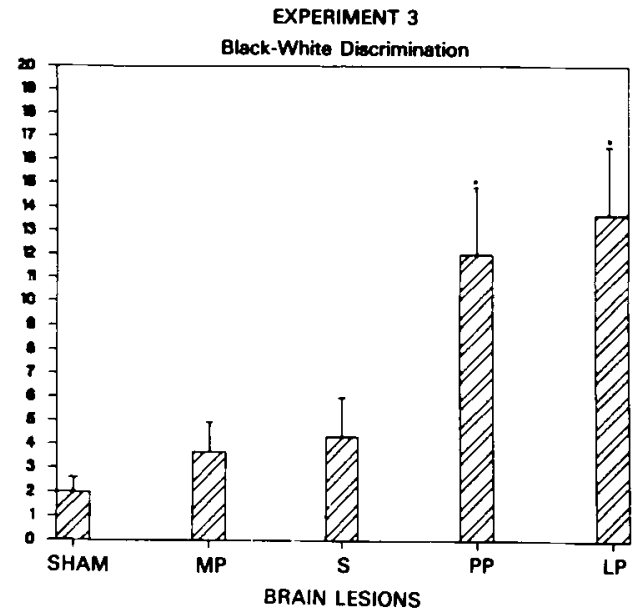

B

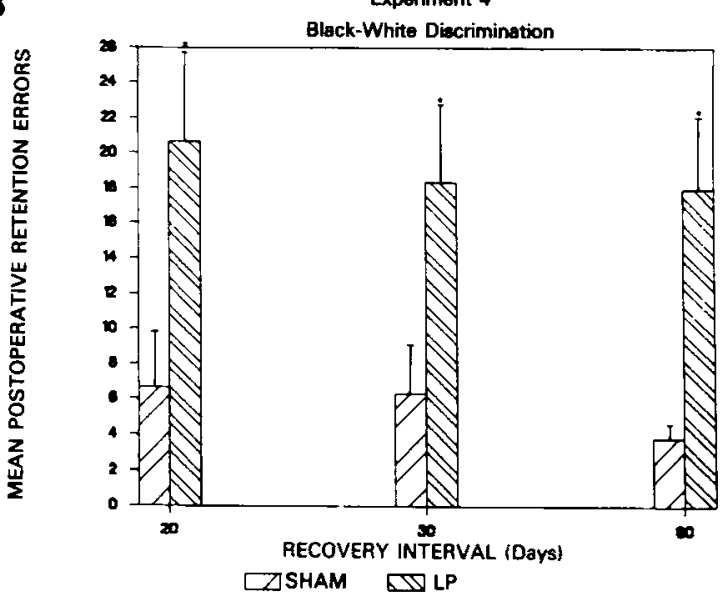

C

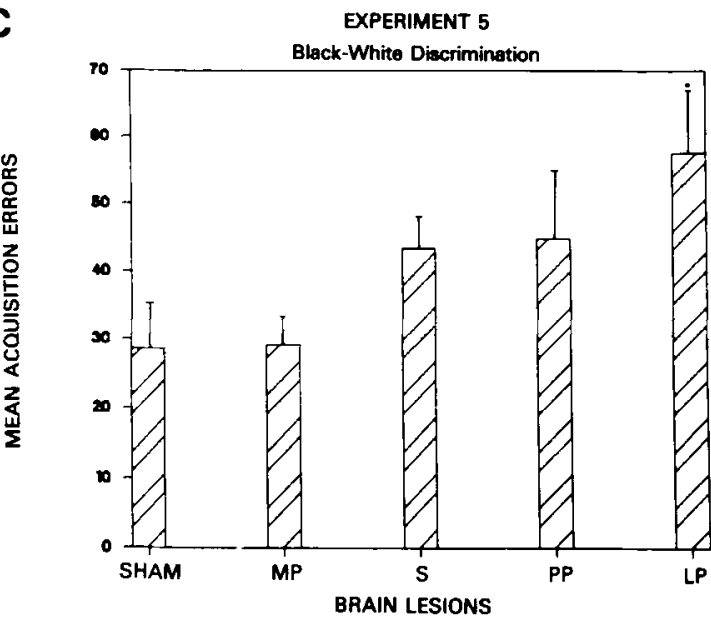

Figure 5. Mean and standard error of the mean total errors on the black versus white card discrimination. Asterisks signify statistically significant differences from controls. Panel A, retention; Panel B, retention by LP-injured rats across three recovery intervals; Panel $C$, acquisition. 
(45 and 43.4, respectively). Fisher's $L S D$ test showed that these two pooled groups differed from one another $[t(20)$ $=2.16, p<.05]$. The animals with LP injuries did not differ from the pooled PP/striate group. Hence, lesions limited principally to LP, PP, or striate neocortices, but not MP cortex, retard acquisition of black-white discrimination (see Figure 5c).

\section{DISCUSSION}

The results of these experiments contribute to the generation of a descriptive catalog that depicts the behavioral consequences of subtotal posterior neocortical injuries in the rat. One clear, albeit not surprising, conclusion is that injuries inflicting little or no damage to the geniculostriate visual pathways can seriously diminish the animal's ability to utilize visual stimuli to guide instrumental behaviors. A summary of these results is presented in Table 1.

Lesions of the LP neocortex have the most devastating effects upon visual functions, possibly because they seriously diminish the acuity of spatial contrast resolution (Dean, 1981). This explanation could account for the performance impairment observed in the brightness, as well as the pattern-vision, tasks. Since it has been found (Cooper, Blochart, Gillespie, \& Miller, 1972) that areas of high spatial contrast (e.g., edges of the black and white cards) rather than luminance differences are utilized by rats to solve the task of discrimination between black and white cards, both acquisition and retention impairments might be expected. It should be recalled that rats with LP injuries demonstrate no impairments in relatively nonvisual spatial tasks (McDaniel, 1985; McDaniel \& Thomas, 1978). The LP neocortex contains at least four retinotopic divisions (Espinoza \& Thomas, 1983), but apparently so far the visual functions of these subdivisions have not been investigated.

Previously we suggested that the LP cortex might play a necessary role in pattern resolution (Lindsay \&

Table 1

Catalog of Visual Discriminations Influenced by Localized Posterior Cortical Injuries

\begin{tabular}{|c|c|c|c|c|}
\hline \multirow[b]{3}{*}{ Lesion } & \multicolumn{4}{|c|}{ Discrimination } \\
\hline & \multicolumn{2}{|c|}{ Black-White } & \multicolumn{2}{|c|}{ Pattern } \\
\hline & Acquisition & Retention & Acquisition & Retention \\
\hline $\begin{array}{l}\text { Striate } \\
\text { (area 17) }\end{array}$ & $\begin{array}{l}\text { Slightly } \\
\text { retarded }\end{array}$ & No deficit & Retarded* & $\begin{array}{l}\text { Loss, } \\
\text { reattainable }\end{array}$ \\
\hline $\begin{array}{l}\text { Lateral } \\
\text { peristriate } \\
\text { (area 18a) }\end{array}$ & Retarded & $\begin{array}{l}\text { Loss, } \\
\text { reattainable }\end{array}$ & $\begin{array}{l}\text { Not } \\
\text { attainable* }\end{array}$ & $\begin{array}{l}\text { Loss, not } \\
\text { reattainable }\end{array}$ \\
\hline $\begin{array}{l}\text { Posterior } \\
\text { parietal } \\
\text { (areas 7, 39, } \\
\text { caudal 2) }\end{array}$ & $\begin{array}{l}\text { Slightly } \\
\text { retarded }\end{array}$ & $\begin{array}{l}\text { Loss, } \\
\text { reattainable }\end{array}$ & $\begin{array}{l}\text { Slightly } \\
\text { retarded }\end{array}$ & $\begin{array}{l}\text { Loss, } \\
\text { reattainable }\end{array}$ \\
\hline $\begin{array}{l}\text { Medial } \\
\text { peristriate } \\
\text { (area 18b) }\end{array}$ & No deficit & No deficit & $\begin{array}{l}\text { Slightly } \\
\text { retarded }\end{array}$ & No deficit \\
\hline
\end{tabular}

*Dean, 1981; Hughes, 1977; Lindsay \& McDaniel, 1987; McDaniel et al., 1982; McDaniel \& Noble, 1984.
McDaniel, 1987). However, Goldstein and Oakley (1987) have observed that, with extensive training, some total decorticates and posterior decorticates can eventually learn to discriminate patterns thought to equate both total and local luminance cues, and this challenges our proposal. Isolation of the structures and mechanisms responsible for such an elusive residual ability to demonstrate resolution acuity awaits further research. It will involve behavioral methods with unconfounded demands that are more sensitive and efficient measures of visual pattern perception ability. Dean (1981) has provided important clues concerning the probable anatomical loci that include the superior coliculus and lateral nucleus of the accessory optic tract.

In contrast to rats with LP lesions, destriate animals given extensive training can demonstrate residual pattern vision (Hughes, 1977; McDaniel \& Noble, 1984). This may be because the acuity of visual resolution is not as seriously diminished in rats with striate injuries as it is in rats with LP injuries (Dean, 1981). The results seen in the black-white discrimination studies might be explained by this model. Impaired, but not abolished, acuity in spatial contrast might retard the acquisition of the discrimination by diminishing the saliency of, and hence behavioral reliance upon, contrast (pattern) cues. A failure to observe a retention deficit reflects not only the preservation of the gross pattern vision function, but also the important role played by education (i.e., learning to resolve relevant from irrelevant cues) prior to neural injury as a means of minimizing compensatory efforts by the animal and maximizing reliance upon injured but still functional neural systems (see LeVere, 1980, for details of this theory).

Medial peristriate lesions resulted in a slight retardation in the acquisition of the pattern discrimination. Since no acquisitional impairment was observed in the blackwhite discrimination, the associational impariment may be limited to paradigms that employ complex stimuli. The excellent postoperative retention of the pattern discrimination observed in rats with MP lesions proves that the integrity of this retinotopic field is not necessary for successful pattern vision. As demonstrated by Pinto-Hamuy et al. (1987), MP lesions disrupt the relearning of a conditional visuosomatic habit. Hence, this region appears important in the formation of multimodal associations rather than simple visual processing.

Animals with posterior parietal injuries were impaired in each paradigm examined except the visuospatial discontiguity task. The failure to detect a marked disruption of discrimination behavior in this paradigm may have been due to the protective influence of the extensive training that the rats received, both preoperatively and postoperatively, on the oblique-stripe task. This experience may have trained the animals to utilize cues within the entire stimulus card, and different results may have been achieved if the stimuli used to create the spatial discontiguity pardigm had been novel.

Interestingly, Experiment 1 confirmed that smaller, more anteromedial parietal injuries are not associated with 
visual disturbances (also see McDaniel, 1985). Whether this observation relates to differences in lesion size or, rather, regional location and lateral extent of the injury awaits further experimentation. Because of the variety of instrumental tasks disrupted by extensive parietal lesions, Thompson and his colleagues (Thompson, Huestis, Crinella, \& Yu, 1986; Thompson \& Yu, 1985) have classified the parietal neocortex as part of the brain's "general learning system." Also, Kesner, DiMattia, and Crutcher (1987), using radial maze methodologies that dissociate working- from reference-memory dysfunctions, have reported that an impairment of reference memory, but not working memory, accompanies large parietal lesions. An interpretation of these conclusions is offered below.

Miller and Vogt (1984) have shown that corticocortical fibers from both striate and extrastriate visual cortices either terminate in or course through regions defined as PP cortex. Many fibers of passage terminate in frontomotor cortices, and as has been shown by Kolb and Walkey (1987), many fibers originating from area 7 of the PP cortex terminate in anterior cingulate and medial precentral cortex. Therefore, it is possible that some deficits observed following massive parietal lesions (i.e., those studied by Kesner et al., 1987, and Thompson et al., 1986) or PP lesions of a sufficient medial to lateral extent (like those studied here) were due to a disconnection of cortical visuosensory regions from cortical motor regions, as well as the removal of the multisensory neurons of area 7. As discussed by Miller and Vogt, such connections would be needed for visuomotor integration. Hence, dysfunctions might be expected in tasks with prominent visuospatial demands, such as uncued place learning in the Morris water task and the 8-arm radial maze (Kolb \& Walkey, 1987), as well as the two-choice visual discrimination tasks investigated here, and each of the four behavioral tests used by Thompson et al. (1986). Additional support for this hypothesis might be found in the results of Kolb et al. (1983) and Kolb and Walkey (1987). In the former study it was found that PP lesions produced only a slight, temporary (first 2 days) disturbance in a measure of short-term memory during acquisition of a radial maze habit. In the latter, PP-injured rats were found to be impaired according to all measures of acquisition in the radial maze. One noticeable difference between these two studies is that the lesions in the latter experiments extended more laterally to include portions of area 39. As suggested by an anonymous reviewer, it is also possible that PP lesions denervate the more caudal posterior cortices of brainstem and midbrain bioamine inputs. The methods used in this study do not permit us to evaluate this important possibility.

Finally, as has been argued previosuly by Dean (1981), McDaniel (1985), and Kolb and Walkey (1987), there are considerable similarities between the organizational features and the behavioral functions of the posterior cortex in both rats and mammals presumed to be more advanced. The comparison of behavioral analogies across species (not to mention within species) is greatly complicated by the varieties of tests utilized in different laboratories.
However, a brief attempt will be made to cite some similarities. The above interpretation of the behavioral deficits associated with PP injuries in the rat are consonant with observations made of primates (Mishkin, Lewis, \& Ungerleider, 1982; Mishkin \& Ungerleider, 1982), and our results strengthen the proposition that the PP cortex in the rat shares many features in common with the PP cortex in monkeys (Kolb \& Walkey, 1987). Concerning the striate neocortex, considerable resolution acuity remains after injury in rats, tree shrews (Ware, Diamond, \& Casagrande, 1974), monkeys (Weiskrantz \& Cowey, 1963), and man (Weiskrantz, 1980). Injuries that extend into prestriate regions reduce resolution acuity, and hence the ability to distinguish visual forms and patterns, to a far greater extent (Pasik \& Pasik, 1971). In monkeys, injuries confined to the prestriate belt have produced conflicting results, but some evidence (e.g., Mishkin, 1972) has demonstrated a severe deficit in object and pattern discrimination. Therefore, on the basis of the literature and the results here, there is sufficient rationale to conclude that marked similarities exist among species of the class mammalia in the organizational features and the behavioral functions of the posterior neocortex.

\section{REFERENCES}

Boyd, M. G., Thomas, R. K. (1977). The effects of posterior association cortex lesions in rats: Mazes, pattern discrimination, and reversal learning. Physiological Psychology, 5, 455-461.

CoOper, R. M., Blochert, K. P., Gillespie, L. A., \& Miller, L. G. (1972). Translucent occluders and lesions of posterior neocortex in the rat. Physiology \& Behavior, 8, 693-697.

DEAN, P. (1981). Visual pathways and visual acuity in hooded rats. Behavioural Brain Research, 3, 239-271.

EspinozA, S. G., \& Thомаs, H. C. (1983). Retinotopic organization of striate and extrastriate visual cortex in the hooded rat. Brain Research, 272, 137-144.

FELLows, B. J. (1967). Chance stimulus sequences for discrimination tasks. Psychological Bulletin, 67, 87-92.

Foreman, N., SteVens, R. (1982). Visual lesions and radial maze performance in rats. Behavioral \& Neural Biology, 36, 126-136.

Gallardo, L., Mottles, M., Vera, L., Carrasco, M. A., Torrealba, F., Montero, V. M., \& Pinto-Hamuy, T. (1979). Failure by rats to learn a visual conditional discrimination after lateral peristriate cortical lesions. Physiological Psychology, 7, 173-177.

GAVIN, M. R., ISAAC, W. (1986). Recovery of function of a conditioned avoidance response in rats with serial and single-stage bilateral occipital ablation. Physiological Psychology, 14, 31-35.

GoldsteIN, L. H., OAKLEY, D. A. (1987). Visual discrimination in the absence of visual cortex. Behavioural Brain Research, 24, 181-193.

Goodale, M. A., \& DALE, R. H. I. (1981). Radial-maze performance in the rat following lesions of posterior neocortex. Behavioural Brain Research, 3, 273-288.

Horel, J. A., Bettinger, L. A., Royce, G. J., \& Meyer, D. R. (1966). Role of neocortex in the learning and relearning of two visual habits by the rat. Joumal of Comparative \& Physiological Psychology, 61, 66-78.

Hughes, H. C. (1977). Anatomical and neurobehavioral investigations concerning the thalamocortical organization of the rat's visual system. Journal of Comparative Neurology, 175, 311-336.

Kesner, R. P., DiMattia, B. A., CRUtcher, K. A. (1987). Evidence for neocortical involvement in reference memory. Behavioral \& Neural Biology, 47, 40-53.

Kolb, B., Sutherland, R. J., \& Whishaw, I. Q. (1983). A compari- 
son of the contributions of the frontal and parietal association cortex to spatial localization in rats. Behavioral Neuroscience, 97, 13-27.

KOLB, B., \& WALKEY, J. (1987). Behavioural and anatomical studies of the posterior parietal cortex in the rat. Behavioural Brain Research, $23,127-145$.

LASHLEY, K. S. (1935). The mechanism of vision: XII. Nervous structures concerned in habits based on reactions to light. Comparative Psychology Monographs, 11, 43-79.

Lavond, D. G., \& Dewbury, R. G. (1980). Visual form perception in a function of the visual cortex: II. The rotated horizontal-vertical and oblique-stripes pattem problems. Physiological Psychology, 8, 1-8.

Lavond, D., Hata, M. E., Gray, T. S., Geckler, C. L., Meyer, P. M., \& MEYER, D. R. (1978). Visual form perception is a function of visual cortex. Physiological Psychology, 6, 471-477.

LEVERE, T. E. (1980). Recovery of function after brain damage: A theory of the behavioral deficit. Physiological Psychology, 8, 297-308.

Lindsay, J. F., JR., \& McDaniel, W. F. (1987). Neural tissue transplants in rats with lateral peristriate lesions: II. Behavior. Medical Science Research, 15, 655-656.

MCDANIEL, W. F. (1985). Functions of the posterior neocortex of the rat. IRCS Journal of Medical Science, 13, 286-289.

MCDANIEL, W. F., \& BROWN, R. G. (1984). Radial maze performance following restricted posterior neocortical lesions. IRCS Medical Science, 12, 807-808.

McDaniel, W. F., Coleman, J., Lindsay, J. E., Jr. (1982). A comparison of lateral peristriate and striate neocortical ablations in the rat. Behavioural Brain Research, 6, 249-272.

MCDaniel, W. F., \& Noble, L. M. (1984). Visual pattern discrimination following bilateral striate or lateral peristriate neocortical injuries. IRCS Medical Science, 12, 1084-1085

MCDaniel, W. F., \& Thomas, R. K. (1978). Temporal and parietal association cortex lesions and spatial and black-white reversal learning in the rat. Physiological Psychology, 6, 300-305.

McDaniel, W. F.. Wildman, L. D., \& Spears, R. H. (1979). Posterior association cortex and visual pattern discrimination in the rat. Physiological Psychology, 7, 241-244.

MEYER, D. R., MEYER, P. M. (1977). Dynamics and bases of recoveries of functions after injuries to the cerebral cortex. Physiological Psychology, 5, 133-165.

Meyer, P. M., Meyer, D. R., Cloud, M. D. (1986). Temporal neocortical injuries in rats impair attending but not complex visual processing. Behavioral Neuroscience, 100, 845-851.

Miller, M. W., \& VoGT, B. A. (1984). Direct connections of rat visual cortex with sensory, motor, and association cortex. Journal of Comparative Neurology, 226, 184-202.

Milner, A. D., Goodale, M. A., \& Morton, M. C. (1979). Visual sampling after lesions of superior colliculus in rats. Journal of Comparative \& Physiological Psychology, 93, 1015-1023.

MishKIN, M. (1972). Cortical visual areas and their interaction. In A. G. Karczmar \& J. C. Eccles (Eds.), The brain and human behavior (pp. 187-208). Berlin: Springer-Verlag.

Mishkin, M., LewIS, M. E., \& UNGerleider, L. G. (1982). Equiva- lence of parieto-preoccipital subareas for visuospatial ability in monkeys. Behavioural Brain Research, 6, 41-55.

Mishkin, M., \& UNGerleider, L. G. (1982). Contribution of striate inputs to the visuospatial functions of parieto-preoccipital cortex in monkeys. Behavioural Brain Research, 6, 57-77.

Montero, V. M., Rojas, A., TorrenlbA, F. (1973). Retinotopic organization of striate and peristriate visual cortex in the albino rat. Brain Research, 53, 197-201.

Pasik, T., Pasik, P. (1971). The visual world of monkeys deprived of striate cortex: Effective stimulus parameters and the importance of the accessory optic system. Vision Research, Suppl. No. 3, 419-435.

Pinto-Hamuy, T., Olavarria, J., Guic-Robles, E., Morgues, M. NAsSAl, O., \& PetrT, D. (1987). Rats with lesions in anteromedial extrastriate cortex fail to learn a visuosomatic conditional response. Behavioural Brain Research, 25, 221-231.

Thomas, R. K., \& PeACock, L. J. (1965). A method of measuring brain lesions. Psychonomic Science, 3, 184.

Thomas, R. K., \& Weir, V. R. (1975). The effects of lesions in the frontal or posterior association cortex of rats on Maze III. Physiological Psychology, 3, 210-214.

Thompson, R. (1979). Hippocampal and cortical function in a maze devoid of left and right turns. Physiology \& Behavior, 23, 601-603.

Thompson, R., Bryant, J. H. (1955). Memory as affected by activity of the relevant receptor. Psychological Reports, 1, 393-400.

Thompson, R., Huestis, P. W., Crinella, F. M., \& YU, J. (1986). The neuroanatomy of mental retardation in the white rat. Neuroscience \& Biobehavioral Reviews, 10, 317-338.

Thompson, R., \& YU, J. (1985). The comparative effects of frontal, parietal, occipitotemporal, and limbic forebrain lesions in weanling rats on learning. Physiology \& Behavior, 15, 559-567.

ToGA, A. W., \& Coluns, R. C. (1981). Metabolic response of optic centers to visual stimuli in the albino rat: Anatomical and physiological considerations. Journal of Comparative Neurology, 199, 443-464.

Torrealba, F., Olavarria, J., \& Carrasco, M. A. (1984). Cortical connections of the anteromedial extrastriate visual cortex in rat. $E x$ perimental Brain Researach, 56, 543-549.

Ware, C. B., Diamond, I. T., Casagrande, V. A. (1974). Effects of ablating the striate cortex on a successive pattern discrimination: Further study of the visual system in the tree shrew (Tupaia glis). Brain, Behavior \& Evolution, 9, 264-279.

WeISKRANTZ, L. (1980). Varieties of residual experience. Quarterly Journal of Experimental Psychology, 32, 365-386.

Weiskrantz, L., \& CoWEY, A. (1963). Striate cortex lesions and visual acuity of the rhesus monkey. Joumal of Comparative \& Physiological Psychology, 56, 225-231.

Whishaw, I. Q., \& KolB, B. (1984). Decortication abolishes place but not cue learning in rats. Behavioural Brain Research, 11, 123-134.

(Manuscript received October 28, 1987; revision accepted for publication May 13, 1988.) 